\title{
The future of Brazilian Biochemistry
}

F.J.S. Lara
Correspondence

F.J.S. Lara

Departamento de Biologia

Instituto de Biociências, USP

05508-900 São Paulo, SP

Brasil

Summary of a presentation made during the XXV Annual Meeting of the SBBq in Caxambu, 1996,

as part of the Round Table

"Biochemistry in Brazil, Past,

Present and Future".

Publication supported by FAPESP. $\ldots \ldots \ldots \ldots \ldots \ldots \ldots$

Received September 12, 1997 Accepted September 24, 1997 ......................
Departamento de Biologia, Instituto de Biociências, Universidade de São Paulo, São Paulo, SP, Brasil
Every scientist works very close to the frontier of the unknown, but never in a vacuum, because of the work of those who preceded him. When writing their research plans, scientists engage in an exercise of futurology. They do not know exactly what they might find or discover although they have an educated idea about the possible outcome of their projects, if executed. The experimental methods we employ are languages we use to establish a dialogue with nature. An experiment is a question we pose to nature. If the question is intelligent and formulated in the appropriate language we will receive an intelligent answer; if not... The situation of a scientist is quite similar to that of the boy in the story. He was fishing from a bridge and a man passing by asked him what he was doing. The boy replied that he was fishing "tiriscos". The man found this interesting and asked the boy what a tirisco looked like. The reply was: "I don't know because I haven't caught one yet."

In order to foresee the future we must know the past and the present with respect to the situation of Biochemistry and of biochemists in Brazil. I talked with Prof. Chaimovich, at the time President of our Society, and I interviewed various renowned biochemists (unfortunately all of them from the city of São Paulo since it is difficult for me at present to move around). I am presenting here the results of these interviews so that they may be discussed more in depth.

The first observation is that there are no concrete data about the professional situation of biochemists in Brazil and therefore there is no basis for an analysis of the current and future trends of our scientific activity. However, even in the absence of precise data, it is possible to evaluate the present and to project some future perspectives.

An analysis of the current situation of Brazilian Biochemistry shows highly negative aspects side by side with highly positive ones. Let us first look at the negative aspects which are necessarily linked to the reality in which we work. We live in a country where the minimum salary is $\mathrm{R} \$ 112.00$, one of the lowest in the world. An appreciable part of our population is destitute and the number of abandoned minors is enormous. Our public schools are extremely poor and the public health system is highly precarious. Organized crime is increasingly becoming a State within the State; our justice system is archaic, extremely slow and unjust. Scandals and killing sprees occur constantly and the guilty run scot free. Our Congress ... it is not worth the trouble to talk about it. I do not want to consider these aspects any longer or how they affect our activities because this article would then become too lengthy and exhausting. It is better to move on to the positive part of my analysis.

Today, Brazilian Biochemistry is internationally recognized. It exists thanks to successful initiatives taken in different parts of the country. However, this was random development: each scientist did what he wanted, where he wanted and how he wanted to. We were successful even though we did not have a scientific policy. Neither the SBBq nor the public agencies elaborated such a policy. As 
the Baron of Mauá used to say: "Those who do not know what they want end up by not recognizing what is desirable when they find it." Our past President, Prof. Chaimovich, believes that we should work in order to have a scientific policy in our field and to determine the path we could follow with higher efficiency. This is not a task for a single man or even for the $\mathrm{SBBq}$ alone, although they could make fundamental contributions. We have the human resources needed to form a series of committees that could study the various aspects of such policy.

Today we represent one of the best prepared and most prosperous activities on the Brazilian scientific scene. There was a qualitative and quantitative jump in the 1970's and we are about to witness a new jump. I refer to the FAPESP program for "emerging talents" which is helping approximately 300 recently graduated doctors from all areas whose careers present promising characteristics by providing laboratories, fellowships and appropriate working conditions. Unfortunately, there seems to be nothing similar in other states, but I must confess that I am impressed by the Brazilian scientific production which has not decreased after the reduction in resources faced over the last few years. The academic situation is quite good although there is a general lack of the infrastructure that might permit a more rational use of resources and personnel. We definitely have a situation that will permit us to prepare for a better future.

In this respect, I see two important challenges to be faced. First of all, we need more creativity; second, we must think of the practical usefulness of our activities.

There are two types of Science: the type that looks for data that will confirm previously established paradigms, and the type, often called "frontier science", that results in the acquisition of data which, by not fitting into the old paradigms, require the establishment of new paradigms that will accommodate them. Brazilian Biochemistry fully be- longs to the first category. We shall have to progress a lot, both in qualitative and quantitative terms, to reach the second category.

We are on the threshold of the new era of informatics. This means that more recent information is available to us at a much greater speed. We no longer need to wait for journals to arrive at the library to consult them. We can read the latest issue of Nature or of any other scientific journal immediately after publication on the screen of our computers, where they arrive through the Internet, or we can print it out. Many journals, especially those in the field of physics, are no longer printed on paper, but only exist in electronic format. This means that each scientist has the obligation of being very well informed. However, we cannot delude ourselves with the velocity at which information reaches us. The true measure of time will continue to be the time needed to reflect about the problems we are attacking. We shall now have more time available for this but our obligations will increase because of much greater competition. "Scientific problems at the national level" will become less and less frequent. At the beginning of this century, Kluyver had proclaimed "Die Einheit in der Biochemie", the unity in biochemistry. The biological processes are essentially the same and follow the same pathways in any part of the world, explaining the universal nature of our science.

Another deficiency we cannot overlook is the essentially academic nature of our Biochemistry. We must face the reality in which we live in a better manner. Man is the primordial objective of any human activity. It is no longer sufficient for an author to have 150 citations of his work in order to belong to a group of outstanding scientists. Brazilian businessmen are historically and culturally used to depending on government subsidies. A little more than one year back, Veja magazine published an article about several newly rich Brazilian entrepreneurs who built their fortunes independently of governmen- 
tal help, a fact proving that such a process is possible in our country.

The policy of replacement of imported material is suicidal. Let us see an example in the sector of informatics. We entered the field of hardware production at the same time as South Korea, when we were in the same situation as that country, i.e., we both had nothing. Today the situation is totally different. Samsung is a Korean company which sells products of excellent quality at competitive prices. In the meantime, many Brazilian companies have closed and Brazil imports high quality instruments from Korea.

Why is Korea so much farther ahead of us in computers? One of the major figures responsible for Korean development is Hyung Sup Choy, as pointed out by Moyses Nussenzweig in an article published in the book "Ciência e Tecnologia, Alicerces do Desenvolvimento" (Cobram, 1994). Sup Choy stated that "Little can be expected from imported technologies if there is no ability to modify and improve them for application in the importing country...". "It is not true that developing countries do not need to have their own research and development, but can simply import technology from developed countries... It is of the utmost importance that these countries will not let themselves be persuaded that the generation of technology is economically meaningless or impossible in developing countries. On the contrary, it is perfectly viable and it is essential that a country be capable of generating its own technology... This requires, above all, highly qualified persons."

How can we do this with underpaid persons with an educational level that does not even permit them to read manuals? Our error was to copy in an attempt to replace, whereas the Koreans tried to create and to produce something better than what already existed. This policy indeed was successful and victorious. If we want to develop a biochemical industry that will employ our graduates, we must adopt a creative policy. We must forget about making efforts simply to do swimming exercises, but we must invest new swimming styles: to think of completely new things on the top of the wave. We have access to information but we do not know as yet how to use it. For this to become possible, we must change our curricula, teaching students to use this information and also teaching them that they should not be ashamed to earn money! We also need aggressive businessmen ready to run risks. I know that this is an enormous challenge, but it is a challenge that the new generation of biochemists and businessmen will have to face. It is not sufficient to increase our academic capacity, we also must return something to our society, which must learn to walk on its own legs.

A young biochemist who will take time to think may invent really new and promising things that can be transformed into socially useful products. What I foresee here is the onset of backyard concerns with low initial costs similar to many initiatives known abroad. I confess that I do not know exactly what could be done; if I knew, I certainly would be doing it. But I am sure that we need new things, we need to be on top of the wave and not copy or do something similar to what was previously invented. I trust the intelligence of our young people, who are our hope for the future. 